lower, than in the CG - $10.1[7.4-16.6] \mathrm{ng} / \mathrm{ml}(\mathrm{p}>0.05)$; IL-1 $\beta$ content - 23.7 [12.4-45.6] $\mathrm{pg} / \mathrm{ml}$ and 8.5 [3.3-46.0] $\mathrm{pg} / \mathrm{ml}$ respectively $(\mathrm{p}<0.05)$; IL-6 level - 84.4 [49.6-194.6] $\mathrm{pg} / \mathrm{ml}$ and $26.5[11.2-79.2] \mathrm{pg} / \mathrm{ml}$ respectively $(\mathrm{p}<0.001)$. In women with obesity, $45(83.3 \%)$ children were mature, $9(16.7 \%)$ - premature. Mean gestational age of mature newborns - 38.4 \pm 0.2 weeks, premature - 33.8 \pm 0.6 weeks $(\mathrm{p}<0.001)$. Body weight of mature children was $3,680.0$ [2,958.0-4,040.0] grams, premature - 2,000.0 [1525-2065] grams $(\mathrm{p}<0.001)$. Median level of $25(\mathrm{OH}) \mathrm{D}$ in mature newborns - $8.8[4.0-14.6] \mathrm{ng} / \mathrm{ml}$, in premature - 4.0 [3.94.5] $\mathrm{ng} / \mathrm{ml}(\mathrm{p}<0.01) ; \mathrm{IL}-1 \beta-20.4[11.2-34.0] \mathrm{pg} / \mathrm{ml}$ and 38.1 [32.0-93.8] $\mathrm{pg} / \mathrm{ml}$ respectively $(\mathrm{p}<0.01)$; IL-6 - 84.6 [56.6-166.8] $\mathrm{pg} / \mathrm{ml}$, versus 64.6 [32.0-161.6] $\mathrm{pg} / \mathrm{ml}$ $(\mathrm{p}>0.05)$. In mothers with obesity, 14 (25.9\%) newborns had intrauterine infection, calcidiol level was 6.4 [4.013.4] ng/ml; IL-1 $\beta$ - 17.4 [9.2-23.9] $\mathrm{pg} / \mathrm{ml} ;$ IL-6 - 92.8 [45.6-190.6] $\mathrm{pg} / \mathrm{ml}$, which is 3.5 times higher, than in the CG $(\mathrm{p}<0.01)$.

Conclusions The vast majority of newborns, born by mothers with obesity, had hypovitaminosis $\mathrm{D}$, these children also had conclusively high level of IL-1 $\beta$ and IL-6. In newborns with intrauterine infection, IL-1 $\beta$ and IL-6 content reaches the highest level versus the CG.

\section{GP241 NEONATAL OUTCOMES FOR BABIES WITH EBSTEIN'S ANOMALY}

Isha Nijjar*, Tarak Desai, Shree Vishna Rasiah. Birmingham Women's and Children's NHS Foundation Trust, Birmingham, UK

\subsection{6/archdischild-2019-epa.300}

Introduction Ebstein's anomaly is a rare form of congenital heart disease (CHD), occurring in less than 1\% of patients with CHD.With advances in Fetal Medicine and Cardiology, Ebstein's anomaly is being diagnosed antenatally. The literature highlights that it can be difficult to predict the prognosis particularly during the neonatal period. Our aim was to review the neonatal outcomes of babies with Ebstein's anomaly admitted to our tertiary neonatal intensive care unit (NICU).

Methods We retrospectively identified all babies admitted to the NICU with a documented diagnosis of Ebstein's anomaly between 01/04/2009 and 01/04/2018. Their outcome data was collected using electronic records (BadgerNet $^{\circledR}$ and HeartSuite).

Results In the last 9 years, ten babies had a documented diagnosis of Ebstein's anomaly. Nine of these were antenatally diagnosed. Four were born prematurely ( $<37$ weeks). Seven babies required resuscitation at birth and eight babies required intubation within the first 24hours of life. Many of the babies had other significant co-morbidities including: hydrops fetalis, seizure activity, ventriculomegaly, trisomy 21 and persistent pulmonary hypertension (PPHN). Two babies also underwent therapeutic hypothermia. All of the babies born prematurely died within the neonatal period. Of the six term babies with Ebstein's anomaly, three were discharged home, two were transferred to the Regional Paediatric Cardiology unit and one died on the neonatal unit. The two babies that were transferred subsequently died at the Regional Paediatric Cardiology Unit. The three surviving infants continue to be followed up. One of these patients is now seven years old and has not required any surgical intervention.

Conclusions In our experience, Ebstein's anomaly was fatal in babies born prematurely. The term babies had improved survival but even this was only $50 \%$. The outcomes in the neonatal period can vary significantly for babies with this diagnosis as highlighted in our case series. Although the numbers are small due to the high mortality rates in this group, it is important that parents are counselled appropriately antenatally so that they are adequately prepared for the poor outlook of babies born with Ebstein's anomaly.

\section{GP242 EARLY ONSET SEPSIS IN EXTRAMURAL HOSPITAL OF MYANMAR(BURMA)}

${ }^{1}$ Kyi San Thi*, 'Zaw Win Moe, ${ }^{2}$ Khin Nyo Thein. 'Yankin Children Hospital, Yangon, Myanmar, ${ }^{2}$ Yankin Children Hospital, Yangon, Myanmar

10.1136/archdischild-2019-epa.301

Introduction Early onset neonatal sepsis is the important cause of neonatal morbidity and mortality. Better understanding of early onset neonatal sepsis in outborn neonates is required for better management and prevention especially in developing countries.

Aim The aim of this study was to study the early onset neonatal sepsis in Yankin Children Hospital, an out born neonatal intensive care unit of Myanmar.

Methods In this hospital based cross-sectional descriptive study, ninety eight neonates with signs and symptoms of sepsis admitted within 72 hours of age were enrolled and after taking informed consent, blood samples for septic screen and blood culture were taken. Standard data collection form was used to collect all demographic data and clinical characteristics of neonates. Bacterial isolates were identified using BacT/ALERT system, and their resistance patterns were studied. Statistical analysis was done with SPSS version 16.0.

Results Ninety eight neonates with clinically suspected early onset sepsis were enrolled. Among them, 55 infants were diagnosed as early onset neonatal sepsis(56.1\%) and these 55 infants were studied in this research. Pathogens were isolated in 22 infants $(40 \%)$. PROM (45.5\%), multiple vaginal examinations (60\%), low birth weight (43.6\%) and prematurity (49.1\%), were common risk factors for early onset neonatal sepsis. Reduced feeding ability (92.7\%) and respiratory distress $(80 \%)$ were common clinical presentations. Blood culture was positive in $40 \%(22 / 55)$ of infants with early onset sepsis, respectively. Staphylococcus aureus (41\%) and Escherichia coli $(23 \%)$ were common organisms. Case fatality rate was $22 \%$ $(12 / 55)$.

Conclusion Staphylococcus aureus was the commonest organism in infants with early onset neonatal sepsis in this study which highlighted that the antibiotics given in early onset sepsis should be effective to tackle that pathogen. The organisms isolated were resistant to commonly used antibiotics like penicillin and sensitive to antibiotics like levofloxacin, amikacin and imepenem. The mortality rate of early onset neonatal sepsis in the present study was $22 \%$ which was needed to be reduced by preventive strategies, early diagnosis and prompt and effective treatment. 